\title{
Article \\ Aesthetics without Objects: Towards a Process-Oriented Aesthetic Perception
}

\author{
Nicola Perullo
}

Citation: Perullo, N. Aesthetics without Objects: Towards a

Process-Oriented Aesthetic Perception. Philosophies 2022, 7, 21. https://doi.org/10.3390/ philosophies7010021

Academic Editor: Fabrizio Desideri

Received: 10 January 2022

Accepted: 9 February 2022

Published: 21 February 2022

Publisher's Note: MDPI stays neutral with regard to jurisdictional claims in published maps and institutional affiliations.

Copyright: (C) 2022 by the author. Licensee MDPI, Basel, Switzerland. This article is an open access article distributed under the terms and conditions of the Creative Commons Attribution (CC BY) license (https:// creativecommons.org/licenses/by/ $4.0 /)$.
Department of Gastronomic Sciences, University of Gastronomic Science, Pollenzo, 12042 Bra, Italy; n.perullo@unisg.it

\begin{abstract}
In this paper, I suggest an aesthetic model that is consistent with anti-foundational scientific knowledge. How has an aesthetics without foundation to be configured? In contrast to the conventional subject/object model, with idealistic and subjective aesthetics, but also with object-oriented assumptions, I suggest that aesthetics has to be characterized as relational aesthetics in terms of process-oriented perception and that this leads to an Aesthetics Without Objects (AWO) approach. The relational nature of processes means that they do not happen inter-, that is, between ontologically delimited and stable entities, but rather they correspond between relations. I will try to show that AWO matches well with the onto-phenomenological-epistemic and relational models proposed by recent theories in different fields of science, especially in the relational interpretation of quantum physics. The field of aesthetics, then, does not indicate perceptual fixed contents-either subjective or objectual properties - rather it emerges from a correspondence occurring in an engaged and situated perceptual movement, an agencing that is prior to any sharp distinction between a perceiver and a perceived. I propose to call haptic this perceptual agencing. In the first section, I describe the reasons according to which the adoption of AWO seems more correct and advisable, both with respect to contemporary scientific models and to the current ecological changes on the planet. In the second section, I portray some characteristics of AWO. In the third section, I argue that AWO calls for haptic perception. In the fourth section, I briefly draw some meta-aesthetics consequences concerning, on the one side, socio-political issues of AWO and, on the other side, the possibility for a theory in an anti-foundational model. I conclude with a proposal: a process-oriented aesthetics approach has to be understood mainly as an art of thinking. This means rethinking and re-evaluating the idea of aesthetics as an artisan thought.
\end{abstract}

Keywords: process philosophy; relational perception; haptic experience; correspondence

Pour ma part, il me semble que la meilleure réponse à cette question est celle offerte par la science, qui, je pense, est la suivante: une pierre c'est pas une chose rigide et statique, le prototype de l'objet lui-même. A la lumière de ce que nous avons appris par la chimie, la physique, la minéralogie, la géologie, la psychologie, c'est une vibration complexe de champs quantiques, une interaction momentanée de forces, un processus qui pour un court laps de temps parvient à garder son équilibre en tant que lui-même avant de tomber à nouveau en poudre, un chapitre éphémère dans l'histoire des interactions entre les éléments de la planète, une trace de l'humanité néolithique, une arme des garçons de la rue, un exemple pour une discussion entre nous, une métaphore pour une mauvaise ontologie, une partie d'une partition du monde qui dépend davantage des structures perceptives de notre corps que du monde lui même, un signe de la sacralité du monde pour un shintoïste et une chose à ne pas jeter le premier pour un catholique - en deuxième ça va! -, et ainsi de suite. Un nœud complexe de ce jeu des miroirs infini qu'est la réalité. Le monde n'est pas fait de pierres plus qu'il n'est fait de vagues qui se déplacent sur la mer, ou des divagations d'un fou. Ceci, je trouve, est la vision scientifique du monde: en connaissez-vous de meilleure? 
Carlo Rovelli

\section{The Onto-Epistemological Scientific Basis for an Aesthetics without Objects Approach}

Beyond its practical utility and its countless applications, beyond its undoubted necessity as an orientation and organization instrument for human life, scientific knowledge has a wider and even more decisive importance: it allows us to broaden imagination and to think about new ways of living. This is one of the reasons according to which philosophy, in its different articulations (ontology, epistemology, ethics and aesthetics), should always at least cast a glance on scientific knowledge. In this paper, my aim is to establish an indirect but strict relationship between some epistemic models taken from sciences and aesthetics molded as a particular perceptual disposition consistent with an anti-foundational scientific perspective. I propose to characterize such aesthetics as process-oriented and relational, that is, as Aesthetics Without Objects [1,2]. ${ }^{1}$ Of course, there is a notable tradition of process philosophy, which has amongst its most important protagonists Spinoza, Bergson, Whitehead, Simondon, Deleuze and Guattari, Massumi: although I will convene some of them in the course of this essay, it is not my intention here to retrace the lineage and the adventures of process thought. Rather, my aim is to use some of its instances especially for aesthetics, since it is not usually at the center of process philosophy. Moreover, in my project for an aesthetics-as-process-oriented perception and relational philosophy, I will even include authors who are not usually considered as belonging to such lineage, such as Dewey, Merleau-Ponty and Wittgenstein.

Just to prevent immediately a recurring and legitimate objection: the relationship between science, mind and perceptual experience is peculiar. We do not have to intend it in a direct way, as if there was an immediate translatability between aspects concerning different planes of reality-the so-called "scientific image" and "manifest image" of the world, as Wilfrid Sellars famously put it [3]. Firstly, however, a clear distinction between science and the world of life is everything but obvious because, after all, it is not that true that we experience - and live in - a world of objects. As Heidegger and then Merleau-Ponty, among many others, already pointed out, we experience and live with things, according to knots and processes with respect to which the fixity of an object appears as an expost classification. The hiatus between "appearance" and "reality" —and then, between aesthetics as the domain of the former and science of the latter-is less clear-cut than it may appear. Secondly, even leaving aside this argument, we can take scientific image and manifest image just as different planes of the same wholeness, connected by indirect and mediated relationships. As Carlo Rovelli stated: "Quantum theory is of no direct help in understanding the mind. But indirectly it may teach us something relevant, because it alters the terms of the problem" [4] (p. 137). This alteration does not entail denying the reality of the concepts that we use in our everyday life. Rovelli warns against such fallacy:

There are concepts that play an important role in our dealing with the world. We can have a good conceptual understanding of them. We know what they mean. But it happens that increased knowledge about the structure of the world shows us that our understanding of the phenomena they designate contains something incorrect. However, there is a modification of the same concept that does play precisely the role as the original concept played [5] (p. 2).

In other terms, if it is true that there is no pure phenomenology independent from our conceptual structure, the reverse is also true; concepts evolve and can be modified by empirical knowledge. Concepts and knowledge are on two different planes, two different orders of reality, but they must go hand in hand. Now, this is true not just for epistemic concepts: also aesthetic concepts are concerned. In fact, aesthetics, as it deals with perceptual reality and with the manifest and sensitive image of the world, cannot ignore how this image continually redefines itself in relation to empirical and scientific knowledge. For example, what we know today about the functioning of the senses profoundly affects 
the ways in which aesthetic concepts such as "beautiful" or "good" should be properly used (I will resume this point in the next section).

Nowadays, the alteration of "the terms of the problem" to which Rovelli's words refer, originates from quantum physics theories but also from other sciences-such as biology, systemic theories, biochemistry-and from disciplines contiguous to the sciences-such as psychology and philosophy of mind. The necessary shift is about the transition from an isolationist conception to an integrated, unitary conception of life and reality. The most convincing contemporary discoveries of science speak to us of symbiogenesis, of holobiont, of cooperation, of a more-than-human world, of ontogenetic turn, of extended mind overcoming the intracranial niche, of the dismissal of the rigid dichotomy subject/object. If all these different theories and disciplines, on the one hand, emphasize the cooperative and relational aspects of reality, on the other, and consistently, they profess an anti-anthropocentric view.

Of course, many important twentieth-century philosophers insisted from different perspectives on these themes with force and intensity: Heidegger, Wittgenstein, MerleauPonty, Benjamin, Adorno, Derrida, Whitehead, James, Dewey, Bateson, Maturana and Varela and others, to name just the most famous and influential ones. Obviously, this long line cannot be enclosed under a label; relational philosophers and process philosophers (such as Heidegger and Bergson, Dewey and Whitehead) do not agree on diverse issues. However, my aim is to draw from very different and heterogeneous sources (I would love to include even others, very different thinkers such as Spinoza and Schopenhauer, but this is not the place for developing the whole inheritance) in order to contribute to a change of paradigm in aesthetics. In fact, in this matter one can easily verify that the prevailing model in aesthetics is still based on the clear distinction between subject and object, lacking a constitutive and radical conception of relationship: on the one hand, aesthetic experiences focus on objects or subjects; on the other hand, aesthetic qualities reside either in the objects or in the subjects. This model has prevailed in modernity especially thanks to the great influence of Kantian philosophy. To avoid a trivial misunderstanding in this regard: describing a subject-/object-oriented model as inappropriate does not entail attributing to it any theoretical "objectivism" and, even less, accusing it of a false representation of reality per se (this would betray the ecological-relational idea of knowledge that we support here). It means, more simply, to highlight some traits that seem unsuitable for the world we inhabit today. I want to stress two major traits. One is the privilege granted for the visual: sight as the noblest sense, the deputed tool for the humans and their more reliable perception of the world, namely a perception-of-objects. The other one is the belief that we live in a solid world, made of solid objects. The belief of vision and solidity plays a paramount role in the subject-/object-oriented model. Relational philosophy, on the contrary, in accordance with the relational scientific paradigm, disavows the belief in a solid world composed of isolated realities, while opening up the pathways for a different conception of reality. It is a trans-sensorial, fluid and interwoven conception that can better answer the issues of the aesthetics of the twenty-first century, in line with the most advanced scientific debates and with the anthropological and social changes of our time.

According to the relational interpretation of quantum theory, "an isolated object, taken in itself, independent of every interaction, has no particular state" [4] (p. 120). This interpretation blows away the idea that the world must be made up of a substance with attributes, and it forces us to think about everything in terms of relations. In Rovelli's words:

Individual objects are the way in which they interact. If there was an object that had no interactions, no effect upon anything, emitted no light, attracted nothing or repelled nothing, was not touched and had no smell ... it would be as good as non-existent. [...] The world that we know, that relates to us, that interests us, what we call 'reality', is the vast web of interacting entities, of which we are a part, that manifest themselves by interacting with each other [4] (p. 68).

The relata of the relations are, in turn, knots of relations. This applies to any entity: "Relations make up our ' $\mathrm{I}$ ', as our society, our cultural, spiritual and political life" [4] (p. 166). 
Consider that Rovelli speaks here of "objects" but, in fact, objects "are its nodes" [4] (p. 70). Now, the concept of a constitutive relationship leads to think and to feel (I will return to this) life in terms of a symbiogenetic open process-that is, a cooperative process. Such a paradigm, more surprisingly, introduces another, even more astonishing fact: the world we inhabit is not solid and stable but rarefied, tenuous and subtle, "made up of happenings, discontinuous events, without permanence" [4] (p. 75). Note: Rovelli adopts here the term "interactions", but, as it has been suggested by different authors (Barad, Massumi, Manning, Ingold), maybe it is not the best word to describe the relational nature of reality and life. Following Ingold, in order to make the relational model and the process-oriented perception cooperate in the construction of an Aesthetics Without Objects approach, I will introduce the notion of correspondence.

It is important to note that the logic of cooperation invites handling the notion of identity in a different manner, since it radically questions the notion of a single, isolable entity. "We have never been individuals": the notion of individual has been disrupted by biological research in favor of a "symbiotic view of life" [6] that overcomes the paradigm of the person as a fixed individuality. In this context, some scholars suggest indicating beings and entities of any sort as a mycelial person; in other words, "ontologically" speaking, there are but knots of relations, being the world fluid and not solid. There is no ground, no fundament, no substances nor fixed objects.

Let us see now why the aforementioned aspects are crucial for an aesthetic that must abandon the subject/object model. According to the Italian theoretical physicist Emilio Del Giudice (1940-2014), the modern civilization, born on the wave of the Galilean scientific revolution, has been conceiving the world as the product of the free play of a priori free subjects or objects. He interestingly remarks that the physical notion of "free bodies" interacting through external forces, a key point in the Galilean-Newtonian revolution, is the natural counterpart to the notion of "free individuals" brought together by a social contract [7] (p. 43). Therefore, modern Western society was born based on a strong emancipatory and liberating impulse represented by the new science, also involving the transition from the old to the new political order and the development of democratic States. Within this revolutionary change, also the modern birth of Aesthetics took place. The enhancement of the subject as "individual" and the accompanying agential freedom was the central axis of this physical-philosophical revolution. The scientific and theoretical possibility of single individuals is an expression of the dualistic model, which found its most prominent promulgator in Descartes. Now, the subject/object model presupposes the existence of individuals (either subjects or objects) who can dynamically interact with each other only under certain conditions (through forces, in the case of physics; through qualitative affections of various kinds, in the case of aesthetics). The individualistic model of society that has shaped modern Western political and cultural forms, thus, is based on inter-actions between individuals: isolated, free, acting individuals. This onto-socioepistemological mindset is still very powerful and reassuring for many reasons. There is certainly the fact that fragmentation and multiplicity create the illusion of individual freedom totally in one's own hands, an illusion on which, moreover, the ideology of modern progress has grown. Del Giudice adds: "the highly conflictual and (at least apparently) non-harmonic nature of today's society makes mechanisms based on the external interaction of well-separated a priori objects more comprehensible and immediately readable to people in their daily life than mechanisms based on the cooperativity and coherent behavior of the elementary components" [7] (p. 43).

However, the above considerations let emerge the need for a radical non-separatist model of living as a whole of feeling/thinking with [8], a unitary conception beyond fragmentation and multiplicity that has socio-political consequences, for sure, but that questions the very articulations of the philosophical field too. In fact, a radical relational perspective affects not just epistemology, ontology, ethics and aesthetics with respect to their specific contents, but also their formation and disciplinary identities, breaking down their rigid confinements (notably, I will discuss some meta-aesthetic issues in the last section). Taking 
the notion of relationship seriously implies opening to the consequences of a participatory and cooperative modality of knowledge, discoloring the barriers between fragmented fields. These domains are different, for sure, but differentiation arises along an ongoing process of cooperation, and it depends on particular functions, saliences and attention to varied aspects of life and experience. In other words, these differences are not points of departure but occurring emergencies. One of the main effects of the fragmented mentality, as we will see better later, is the illusion of the rigid separation between ontology and epistemology. However, as Karen Barad aptly puts:

We do not obtain knowledge by standing outside the world. We know because we are of the world. We are part of the world in its differential becoming. The separation of epistemology from ontology is a reverberation of a metaphysics that assumes an inherent difference between human and nonhuman, subject and object, mind and body, matter, and discourse. Onto-epistem-ology — the study of practices of knowing in being-is probably a better way to think about the kind of understandings that we need to come to terms with how specific intra-actions matter. Or, for that matter, what we need is something like an ethico-onto-epistemology - an appreciation of the intertwining of ethics, knowing, and being" [9] (p. 185).

As we read, this list does not mention aesthetics, and it is no coincidence. Aesthetics has suffered more than the other philosophical fields from the modern separationist illusion, and that is why we need to establish a more explicit space for it to be included into the arguments proposed by Barad, Del Giudice and Rovelli.

However, the unitary picture described above has even more radical implications. First of all, we should replace the notion of ontology with the one of ontogenesis. In an ontogenetic paradigm, in fact, subjects and objects are not fixed, well-shaped and bounded entities, pre-established starting points, but temporary and functional crystallizations of ever-forming processes. If there are not enclosed boundaries between "identities", then there is no rigid separation between the internal and the external. As Andy Clark stated, the extended mind is a "wideware" [10]. In his turn, Alva Noë, criticizing the reductionist view that confines the mind to the brain as an intracranial object, observes that the evolution of cognitive sciences clearly shows, instead, the occurrence of life "out of our heads". Elaborating results particularly from biology, Lisa Heldke suggests considering humans as donuts and, hence, proposes a new concept of personhood based upon our kinship with parasites and microbiomes [11]. In the same line, Andreas Weber, following Marcel Mauss' notions of the gift economy and reciprocity, describes one whole, possible society, including all the non-humans, as "metabolic commoning" in which everything is transformed and regenerated thanks to reciprocity and the ultimate gift of death [12].

Let us now return to the notion of interaction and conclude the previous argument regarding its inadequacy to describe the relational and process-oriented model of reality and life here at stake. In fact, we are relations and not in relation. If cooperation is not just an ethical or political option but the major aest-ethico-onto-epistem-ological feature that characterizes life as a whole, if every living thing is made up of bundles of relationships, then relation qua cooperation is not inter-action but something different: Barad proposes "intra-action", Ingold "correspondence". I welcome the latter proposal: "Interaction is between; correspondence in-between" [1] (p. 154). Of course, here "correspondence" does not mean adaequatio rei et intellectus nor the imposition of a form onto a matter; we can describe it, rather, as a kind of resonant perception that rises along the continuity of the experiential flux. In contemporary physics, there is a well-known notion-entanglementthat describes the interdependency of such perception, as I will detail later: it is a perceptual disposition that welcomes and conforms to the rhythmical doing and undergoing (to recall Dewey's couple) of experience.

Once we accept relational reality and process-oriented perception in terms of correspondence, then the interactionist view appears as stubbornly enmeshed in the subject/object and isolationist mindset through which world and life are still largely thought. 
Inter-action seems to be an unintentional relic of the Cartesian and Newtonian model: a possible relationship between fragmented, isolated and self-identical entities, a relationship between entities that is driven by a principle of movement-the force-which is external to them, except for the human subjects, the only real agency owners.

The relational and process-oriented view of aesthetics we aim to suggest takes the radical intertwining of ontology, epistemology and ethics seriously and, at the same time, tries to develop the consequences of the previous observations: cooperating is not implementing interaction policies but ongoing correspondences in a whole and more-than-human-world. However, now, we are faced with a curious fact: there is an important philosophical movement named "Object Oriented Ontology" that considers "correlationism" to be just a version of the modern human-centric subjectivism, whose main protagonist is Kant [13]. However, what we have said so far supporting the relational and process-oriented perception is precisely addressing the overcoming of the modern human-centric objectivism and subjectivism, in favor of a "more-than-human" approach. Let us delve into this oddity.

\section{Main Features of Aesthetics without Objects}

Nowadays, many philosophers and theorists aim at challenging the anthropocentric and human-centric view that has been dominating the philosophical scene of modernity. One of the best-known positions is the so called "Object Oriented Ontology" (OOO, an expression coined by Levi Bryant and taken up by Graham Harman). Actually, OOO is part of a larger and influential philosophical movement identified under the label "speculative realism", which includes a number of different thinkers such as Quentin Meillassoux, Timothy Morton, Levi Bryant, Graham Harman, Markus Gabriel, Maurizio Ferraris and others.

I will use $\mathrm{OOO}$ as a generic label to address, in a quite simplistic way, the belief in a clear separation between ontology and epistemology, and the belief that objects are "in themselves" regardless of their relationships. I am aware that some of OOO's elaborations (I think above all of Morton's work) are in line and can cooperate with this project that, stemming from relational philosophy and process-oriented perception, leads to an aesthetics without objects. However, my point concerns whether to think of humans as "objects" (or "hyposubjects", in Morton's words) or, rather, as bundles of relations, knots of "lines of correspondence" (in Ingold's words). As I will show, this second option is better, because postulating an independent essence and reality of the objects-even if considered in order to underline their unattainability, that is, the fact that we can never grasp such objects, the fact that they remain "dark" —is, malgré soi, an anthropocentric move. Pointing out the human insufficiency of grasping reality, in fact, means precisely continuing to think of the human as a special being. The inability to grasp a reality of which one is nevertheless aware of the existence is a way to reaffirm, albeit in a negative way, a certain form of superiority $[14,15] .^{2}$

Beyond anthropocentrism, another main objective of $\mathrm{OOO}$ and speculative realism is the reductionist tendency of modern Western philosophy for classifications and taxonomies that catalog the world just on the basis of human perception. However, again, also relational and process philosophies, as well as relational sciences, fight against a reductionist conception of reality. Again, it seems, at least apparently, that two opposing strategies of thinking make the same criticism of the same controversial objective. How is this possible? Although here I am not dealing with a detailed examination of such possible controversy, I will briefly discuss two salient points in relation to aesthetics, which, according to many OOO theorists, is fundamental, or even "the root of all philosophy" [16] (p. 61).

Let us first consider relationalism (I prefer it to "relationism", because the latter normally indicates the theory according to which relations are substantial realities per se, while, according to the former, the relational nature of reality includes the nature of relations themselves: relations are not substantial structures). As we have anticipated above, relations do not necessarily occur between a human agent/perceiver and non-human entities. Although this is a reductive and incorrect picture of relationalism, OOO ascribes anthro- 
pocentrism to relational philosophy, as if the interwoven and unitary nature of reality, life and experience necessarily require an act of devouring assimilation by an agent/subject. However, as the relational interpretation of quantum physics depicted above makes it clear, a relationship does not occur between an observing consciousness and a specific physical system, but between a certain physical system and another physical system. There is a relationship between the cat next to me and me; between the cat and the tree where it left its ball; between the tree, the stone lying below and me. To make a different example, there is a dynamic field of relations between the taster and the wine, as well as between the wine and its glass, between the glass and the temperature, between the temperature of the environment and its smellscape, and so on. On a different plane, Merleau-Ponty, pointing out that the world is not in front of me, but all around me, has opened to a similar perspective: human perception is not at the center of relationships, but it constitutes a partial perspective. Today, scientists and theorists (such as Bruno Latour) agree that this

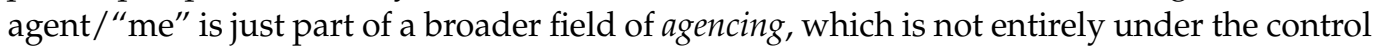
of the human. Relationship is not frontal; it is lateral, above, below and all around.

Quentin Meillassoux, one of the major exponents of OOO, holds co-relationism responsible for the inability to describe the world "as it really is", independently of human knowledge. However, what precisely could correspond to a description of reality that was independent of human knowledge and before any human access? It seems an unsurpassable problem, unless we resort to tools external to philosophy as logos and as rational discourse: for example, those of mysticism or of (a certain conception of) art. In fact, these authors resort to the classic distinction between appearance and reality, notably to the old tool of noumenon: the noumenal essence of the "thing-in-itself" is the black box by Harman or the ancestral realm by Meillassoux. In addition, here is where art comes to the rescue: aesthetics—as a philosophy of art-should fill the gap and offer us the access key. Harman states that "art consists precisely in giving us this noumenal realm in person" [16] (p. 71). The aesthetics that we propose, instead, does not primarily coincide with a philosophy of art and, above all, is not the missing link that has to fill the gap. Process-oriented aesthetics indicates a field of a particular kind of relationships that occur along the continuous and intertwined fabric of the experience. It is the same fabric where ontology, epistemology and ethics operate, with differentiated but corresponding dispositions and interstices; it is an ontogenetic, and then a morphogenetic, fabric in which there is no room for any subjectivist and human-centric position. Relational aesthetics deals with process-oriented perception, that is, with the ongoing creation of morphogenetic perspectives: despite Meillassoux's remarks, no description is possible out of a perspective. Although non-human companions are not there for us, we describe reality from the perspective we are in, and we cannot escape it; it is not a matter of hierarchy but of immersivity. Perception is always from within; thus, relational and process-oriented aesthetics is a feeling/thinking with, an immanent and corresponding aesthetics from within.

The second issue concerns the presumed independence of objects. In the relational model, objects never "exist" per se; they are never autonomous just as subjects are not. This leads us to mind the fact that the concept of independent existence, of an existence as-such, isolated and autonomous, is a formal logical concept, as long as life is not associated with it. However, when existence is infused with life, then objects occur, go on and live [1] (p. 16), so that they are not "objects" anymore but living or things-in the Heideggerian sense: whether we use them or observe and contemplate them, we are always in relation with them. The opposite is also true: they are agential actors too, so they are in relation with us and with their other companions. In OOO theory, real objects are so autonomous and walled up as to "withdraw" without being touched: according to Harman, objects never touch and never relate. However, an object that does not touch anything nor is it related to anything is a lifeless object: an ontologically pure essence beyond any sensitive, sensuous, vital quality. Instead, relational and process-oriented aesthetics is not so much interested in formal or transcendental logic as in an ecological logic, adopting a phenomenological-pragmatic approach [17]. I believe that here lies the greatest disagreement between the process- 
oriented approach and the object-oriented one. In addition, because of that, it is reasonable to argue that the general architecture of OOO theory (despite its numerous variations and adjustments that have been made over time) is an academic philosophy in disguise, as it believes more in the powers of formal logic than in the passages of concrete experience. With its purely logical-deductive arguments, OOO gets stuck inside the dualistic-and ultimately subjectivist-model against which it fights. In the end, I agree with Nicolas Bourriaud when he argues that $\mathrm{OOO}$ is the extreme attempt of an anthropocentric mindset to dominate [18] (pp. 7-15), apparently denying itself but maintaining instead full rational control with the move to keep all objects separate: divide et impera!

Another aspect deserves attention. Within the architectural frame of OOO, a doubling strategy is continuously at work (which replicates the doubling inherent in the subject/object dualism from which we have started): the phenomenal object (the "appearance") on one side, the "real" object on the other. On these presuppositions, the unattainability of that object, that cat, that tree, that rose is fully certain, but those concrete lives are lost as well. I think that this fallacy has brought Jane Bennett to propose the notion of "vibrant matter" —instead of "object" - in order to develop her more-than-human ecological theory [19]. On a similar assumption, we meet Barad's idea of the entanglement of matter and meaning [9]. Moving from the close intertwining between knowledge and life, relational aesthetics moves in the fluid fabric of the morphogenesis of reality, so it is not interested in focusing on the objects per se. Occurring perceptions-feelings, emotions, passions and thoughts-are observed in their correspondence, that is, in their continuous connection and differentiation. As it does not concern ontological objects but ontogenetic processes, in which those crystallizations perceived as "objects" also emerge, this view of aesthetics is Aesthetics Without Objects (AWO). AWO, feeling and thinking life and reality as a whole and celebrating its abundance without the need of an engulfing subject, from OOO, accords a prevalence of the continuous over the discrete. Now, note that although quantum physics states the granularity of reality, made up of discrete entities, nevertheless these entities are not isolated but always, at different grades and extents, related. AWO then, calling for a process-oriented perception along the wholeness of the continuum where differences emerge, is an ecological aesthetics.

Let us return to the strategy of doubling highlighted above for making a step further. As we have said, the aesthetics of $\mathrm{OOO}$ is based upon a logic of doubling; on the contrary, in $\mathrm{AWO}$, aesthetic properties are relational, and there is no guiding doubling. I can explain this point using a Wittgensteinian approach: we can assume that the OOO distinction between "real" and "sensual" properties lies just in the grammar of contingency that emerges along the lines of experience. In other words, there are different properties, but these are left to the concrete relationships occurring along the very fabric of lines of experience. Differences do not indicate any unattainable "black box" and are not predetermined in advance. Relational and process-oriented aesthetics considers the aesthetic field as the ongoing formation of particular qualities that satisfy certain characteristics. This is hardly understandable without leaving the subject/object paradigm, but, on a more general level, mind that, if what we scientifically know and what we phenomenologically perceive are nothing but relations, the fact that there are no objects implies that there are no subjects either: no doubling strategy is at stake here. In order to accept AWO, one has to leave aside the Kantian phenomenalism and its approach that starts from a face to face between subject and object, which finds them in relation afterward, exactly as it is for Newton's physics. Therefore, AWO is also an AWS, an Aesthetics Without Subjects-meaning by it, once more, the isolated, enclosed and autonomous individualities that we call "I". AWO does not begin from any $I$, as agency does not lead but follows a broader agencing. The particular perspectives perceived belong to such an agencing field and, at the same time, contribute to its formation: that perspective of that perceiver is part of the becoming in which (s)he participates. Aesthetic properties and aesthetic values are the provisional forms created along the lines of the rhythm of undergoing and doing in each peculiar encounter; they are 
the vibrant and correspondent resonances in the contingency of every experience. Because of it, they are both spontaneous and skilled, both free and binding [20-22].

Hence, in the AWO model, any rigid ontological boundaries between the different entities-I/non-I, mind/world, spirit/matter, etc.—dissolve. "Self", "Identity", "Personhood" are-ontologically speaking—quicksand. These notions remain fluid and open, onto-phenomenological differentials; they are part of the "wideware", the notion introduced by Clark for explaining the collusion between brain, body and the world [10]. Of course, one can keep going to talk of "identity" and "personhood" - not as ontological concept but as stories carried on from within, as they go along the same indeterminate and shared world [23]. In the same way, one can continue to talk of "individuality", as individuation, following Simondon. Let me anticipate something that I will stress later: this aesthetics opens up important ethical and political consequences. In fact, while questioning the notion of identity, AWO cannot think the difference in terms of otherness and alterity: in its strong sense, alterity presupposes an equally strong identity [24]. Correspondence is not a relation between others but along the whole unity of life continuously differentiating. The couple identity/otherness is still a subject-oriented thinking, and this is why OOO, against its purposes, risks falling into anthropocentrism: an isolated and untouchable object presupposes an equally powerful subject. Of course, Harman and the others would strongly deny it, saying the point is precisely that humans are objects too. However, it remains difficult to understand how one could consider an object/human that perceives, thinks about and acts upon non-human objects if not precisely a perceiving subject. As Ingold aptly noted, "correspondence is about togethering; interaction is about othering" [25] (p. 41). Now, here comes cooperative aesthetics again: aesthetic experiences are, for sure, always "first-person" experiences, but "first-person" does not necessarily coincide with the self and with individual identity. (I will tackle this issue more closely later.)

The notion of cooperation clears the way to a better characterization of the extended mind. According to process-oriented aesthetics, as we have seen, the aesthetic properties develop along the aesthetic experiences, according to those relations, which are resonant correspondences. This means that in aesthetic experiences a particular correspondence takes place between bundles of lines (the "perceiver" and the "perceived", the "environment", the history and the spatial determinations, etc.) in which, at the same time, aesthetic properties are recognized and created. Beauty, for example, is always recognized and created at the same time. Now, in this sense, we can undoubtedly argue that the extended mind is aesthetic, and that the aesthetic mind is extended; however, we have to be very careful not to ontologize and substantialize this notion in turn, thus making mind and world interact rather than correspond. In the aesthetic experience, the correspondence between mind and world is not a doubling between two distinct notions: mind and world belong to the same fabric; in a sense, they are the same thing. As Dewey stated, mind is a verb. Collusion is not between but in-between mind and world. Correspondence is not fusion, but the continuous formation of differences in a shared world. In other words, mind and world do not overlap and intersect because they are whirling movements of agencing. We are whirlpools of becoming that, in certain circumstances, correspond in vibrant and resonant ways: "it is not an object that moves but the emergent form of a movement" [26] (p. 236). Emotions, sentiments, and thoughts emerge and are created along this movement. Think, for example, of the experience of the meal: in a doubling mindset, food is merely consumed, "disappearing" as a visible object, but certainly not in terms of its vibration and correspondence within the ecology in which it operates. Food is a knot of relationships that, upon encountering a gustatory perception, carries on its processes of formation and transformation, as its physical and mental effects clearly show. According to $\mathrm{AWO}$, then, one has to overcome the equation "permanent object = visible presence", with all its representational assumptions: in the case of the aesthetic experience with food, aesthetic values also embrace digestion and metabolism [27].

Consistent with what we have observed, AWO does not pose any hierarchy between some particular domains - the ones falling into the slippery category of "art" —and others- 
those everyday experiences that are then subjected to the division between the "purely" sensitive, the pleasant and the beautiful (as it is the case for Kant, but also for Harman). As we have seen, the possibility of aesthetic experience does not depend on particular contents, whether they are attributed to the powers of a subject or an object. In fact, a symphony, a caress, a gesture or a glass of wine can be in the same way at the center of the aesthetic field [28]. In this sense, one famous definition of aesthetic perception given by Dewey through the case of taste clarifies this well:

As production must absorb into itself qualities of the product as perceived and be regulated by them, so, on the other side, seeing, hearing, tasting, become esthetic when relation to a distinct manner of activity qualifies what is perceived [29] (p. 49).

Tackling concepts such as correspondence, resonance, collusion and extension, issues relating to time and space obviously emerged. As we have tried to clarify, in the AWO paradigm, every aesthetic experience is always ecologically situated but, simultaneously, is part of the same whole fabric, a radically shared world that does not allow for the subdivision into multiple ontologies typical of $\mathrm{OOO}$, a world where differentiations are generated from and, in turn, generate any variations, in a continuous intertwining of the old (lines of experience coming from "the past") and the new (lines of experience going to "the future"). One important consequence is the following: in the AWO model, each aesthetic encounter, being local and site-specific, expresses a local truth that arises between the old and the new, bindings and freedom, within a grammar of contingency. This is the first assumption of AWO: far from relativism, the real is, rather, relational, hyperreal and sur-real, greatly exceeding objectivity as it is infused with life. A relational and process-oriented aesthetics is without objects precisely because it is a perspective disposition towards (hyper-, sur-)reality. It means that it goes beyond the determined and crystallized objectivity, letting emerge (through a certain disposition of perception, that we will discuss later) the determining affordances of a field of correspondences. When the movements between different lines along the experience (i.e., that " $\mathrm{I}^{\prime}$ and that "piece of music") correspond, resonate and collide, they become aesthetic values. In the AWO frame, in other words, aesthetic experience flourishes every time a resonant and correspondent experience between a perceiving (which is not a subject but a perspective node of relationships in an ecology) and a perceived (which is not an object, but another knot of relationships in an ecology) occurs. Therefore, aesthetic perception, being not subject-driven, also "discards" the crystallized object, putting it back in the processual field from which it comes and thanks to which it lives. Aesthetic perception is eco-logical and not ego-logical. When the "subject" melts, disposing itself into the field of affordance of its relational bundle, it can take over phenomena as processes and not as objects.

Now, the extended mind is aesthetic precisely in that it thins the individual perception, the "self". The extended mind thus corresponds to the ecological mind, that is, to the world as a whole, not as fusion but rather as polyphonic interweaving. An aesthetic experience, thus, is an opening to the world as a whole in the most specific and local of the situations; it is the occasion for experiencing the awareness of intimacy [30] and collusiveness [31] with the world, without objects. At the same time, such collusion is exposed and vulnerable, as it is an intimacy between strangers, as Barad stated; that is, it is a correspondence between un-known entities. Because of this, in AWO there is not even a sharp distinction between perception and imagination, and, in any case, in the aesthetic experience, cognition and recognition do not play a prevalent role; sometimes they do not play a role at all while, in other occasions, they cooperate with the ecology of the experience.

According to the correspondent nature of reality, then, localization of aesthetic experience does not concern a fixed point with a precise contour. As we have said, the experience-with of the aesthetic perception is site-specific and local but, simultaneously, being processual and intimately constituted of bundles of lines of heritage and growth, it is universal. This is exactly where ecology leads us: ecology is at the same time local and universal. Ecological knowledge and aesthetic perception go together. On the contrary, in 
the frame of $\mathrm{OOO}$ and its aesthetics, based on the overlap between reality and analytical measurability typical of modern physical science, knowledge and aesthetic perception go together in the opposite way: they follow general principles but, at the same time, they are fragmented, isolated and individual. They are not ecological but ego-logical. In the feeling/thinking with of process-oriented-perception without objects, the engagement unfolds the most specific situation and its universality. Mind the difference between universality as wholeness, on the one side, and generality as uniformity, on the other side. The former recalls a principle of holistic unity, the latter of calculation and juxtaposition. Think of a very simple example: the experiences of beauty or of love are paradigmatic cases in which singularity and universality go together, and this unity concerns both space and time. Once again, we can resort to the relational interpretation of quantum physics: time and space do not exist "in themselves", but only in relation to a perspectival perceiving [9] (pp. 178-185). However, what does it mean to say, in this perspective, that time does not exist? In Rovelli's words:

The absence of the variable time from the fundamental equations does not imply that everything is immobile and that change does not happen. On the contrary, it means that change is ubiquitous. Only: elementary process cannot be ordered along a common succession of instants. At the extremely small scale of the quanta of space, the dance of nature does not develop to the rhythm kept by the baton of a single orchestral conductor: every process dances independently with its neighbours, following its own rhythm [32] (p. 154).

Even in the AWO model, as we have seen, aesthetic experience is simultaneously "independent", that is, singular and site-specific, and related, in its correspondent ubiquity along lines of affordances. Becoming is ubiquitous, but becoming is not time as a succession of instants; maybe, aesthetic experiences present time rather as duration. Process-oriented aesthetic experiences are extended in their own becoming: extremely localized-specific, unrepeatable and insubstantial — and dispositionally diffused, resonant, entangled with other occurrences. Wholeness and differentiation of time and space affect the aesthetic perception in terms of a voluminous - not a volumetric [33] (pp. 94-99) —approach to qualities, acknowledging their contingency and their opacity (what we call "history"): affects, passions, cares, gestures, "infrathin" [34], well beyond the pure logical form of the argument in which one covers up OOO. From all this it follows that AWO does not lay the foundation for an explanatory theory: since aesthetic truth is always local, it can be described and narrated. However, narration, again, is cooperative: it is not the narration guided by an individual subject, a narrating self. Aesthetic narrative (I will return to this in the last section) does not necessarily concern the verbal precipitate of a human perceiver; it has more to do with the memory of collective wholeness.

\section{Aesthetics without Objects as Haptic Perception}

AWO suggests a perceptual distortion of the common approach. In order to describe a process-oriented aesthetic experience as correspondence, we have resorted so far to different auditory-tactile terms such as "vibration", "resonance", "collusion", "intimacy". Such metaphors, however, are not to be taken as the revenge of the auditory and tactile paradigms over the visual one. There is no hierarchy of the senses in AWO: also smell and odors, for instance, play a role, offering an alternative to the conventional prevalence of the visual perception. Notably, AWO is in tune with the fluid dimension provided by odors and their aerial medium, questioning the idea, as we have already stated, that reality is solid. Smell, thus, can deeply contribute to challenge the status of "individual being" understood as a clearly bounded entity and, instead, to open up a relational paradigm, although there exists, of course, also an "Olfactory Objects Theory", which in many points shares the same general assumptions as the OOO. Anyway, AWO avoids proposing again the conventional model of distribution of the sensible, with its categories and taxonomies. If - following Merleau-Ponty's lesson-life is perception and-as Whitehead and Bergson have taught- 
reality is process and movement, it is therefore necessary to conceive feeling/thinking with as plenary and unitary perception.

I propose to call this perceptual attitude haptic perception. "Haptic" is another tactile term, but, differently from "touch", it indicates a peculiar perception. In fact, it goes beyond the grasping of the hand, encompassing all the senses and the whole kinesthetic processes. It is a feeling/thinking with that is wholly (and not punctually) engaged, always touching/touched and participating. The field of haptic is gaining more importance nowadays, but its most common applications do not so much concern philosophy but digital technology, information technology and robotics (from medical prostheses to games), as well as media theories. However, aesthetics and art criticism began long ago to deal with the haptic with respect to visual art. Art historian Alois Riegl was the first to use it explicitly to describe tactile vision, and, more recently, Deleuze and Guattari chose "haptic" instead of "touch" because of its greater adherence to diffused perception, not punctual and without organs [35]. Stefano Harney and Fred Moten, in their turn, in the context of their theory of blackness, define hapticality as "the capacity to feel through others, to feel through you, for you to feel them feeling you" [36] (p. 98) (see also [37]). ${ }^{3}$

The conventional paradigm of aesthetic experience is based upon the subject/object model and on having an experience-of something: it is an optical (retinoic) approach, in which one perceives particular contents as vectors of their aesthetic qualities and appreciation. This is the separatist paradigm of the discretum. In the relational and process-oriented aesthetic experience, instead, we find a with-y perception of a singular experience that is also shared and universal [38]. When Merleau-Ponty writes in Eye and mind about the painter's sight, he refers to this experience: to see the sky means to see with the sky, to merge with its light and presence in a relationship of reciprocal affection [39] (p. 186). This is the plenary paradigm of the continuum, and haptic perception tries to place here. The human mind continuously struggles between the poles of the discrete and of the continuous: when the discrete prevails, the mind works by calculation, fragmentation and assemblage. Instead, the prevalence of the latter places the mind into the conscious attention of correspondences with the world, that is, in the intertwining of feeling/thinking that is an integral "dance of attention", in which the "subject" of the experience is not the human per se but the actual, whole field [40] (p. 14).

Haptic perception affords the sense of the continuum and opens up to a trans-sensory, ecological conscience. Consequently, it does not accord a particular privilege to sight; rather, it is inclusive and tentacular. Haptic perception concerns whole-sentient beings and processes and operates in a "tentacular way" [41] for feeling/thinking sideways, holding back every intention and every project as they instead emerge through the dual split caused by frontal subject/object perception. Perceiving haptically means to soften one's focus, "letting the field's changing configuration dilate to fill experience. You have to let what is normally your peripheral vision take over, attending to everything in the same way" [40] (p. 10). Haptic perception observes without objectifying and explores without evaluating. Evaluation can occur as just one of the possibilities of the experience.

It is important to note that haptic does not necessarily imply physical contact or material presence. It has to do, rather, with a peculiar dis-position and ex-position to the experience, a participant and adherent observation to the currents of life. The haptic perception concerns being present to the inhale/exhale rhythm of life in its interdependency. That is why haptic has more to do with feeling any kind of connections and relationships, even of what is physically or materially absent, than with "touching" the flesh of the bodies. Many bodily experiences and physical contact encounters are not necessarily haptic. Therefore, AWO is no more materialistic than it is idealistic: each of these terms presupposes that logic of doubling which is precisely what AWO rejects. Haptic perception is always engaged and abandons the presupposition of the distance between the observer and observed, endorsing the "aesthetic engagement" modality as participation with the experience [42]. However, aesthetic experience can take place in a multitude of different manners, because presence cannot be measured neither in terms of material reality nor in 
terms of objective reality. According to AWO, then, aesthetic experiences are haptic because they operate primarily in a pre-predicative way, free from any cognitive determination [31], if by this we mean a distinct intellectual agency. Of course, judgment and evaluation can occur, but they are not predetermined categories settled in advance, rather articulations, effects and crystallizations of a wider process. At the same time, haptic perception is never purely "sensible" or "material": against any doubling and distinction between sensibility and cognition, materiality and ideality, haptic perception expresses the unity-indifferentiation of the whole fabric in which all the interstitial differences between sensibility and cognition, materiality and ideality, affects and thoughts, emerge from within.

We have now to come to the role of those grammatical concepts used to express feelings, gestures, judgments, appreciations and evaluations. As we have seen, words are not at all necessary in aesthetic experience; they are just possibilities that emerge in the field, movements along an ecology of experience. "They can be used just as interjections", as Wittgenstein pointed out [43] (p. 3). Actually, AWO finds an important source (as far as my preferences are concerned, the most convincing one) in his Lessons on Aesthetics. In these observations, Wittgenstein presents a large number of examples, recalling or even imagining possible cases of aesthetic appreciation, in order to show that it has no essence at all. Aesthetic appreciation is groundless and objectless; it never pre-exists its formation during the event within an overall ecology. Here are some enlightening passages:

Language is a characteristic part of a large group of activities - talking, writing, travelling on a bus, meeting a man, etc. We are concentrating, not on the words 'good' or 'beautiful', which are entirely uncharacteristic, generally just subject and predicate ('This is beautiful'), but on the occasions on which they are said-on the enormously complicated situation in which the aesthetic expression has a place, in which the expression itself has almost a negligible place [...].

It is not only difficult to describe what appreciation consists in, but impossible. To describe what it consists in we would have to describe the whole environment. [...]

In order to get clear about aesthetic words you have to describe ways of living. We think we have to talk about aesthetic judgements like 'This is beautiful', but we find that if we have to talk about aesthetic judgements we don't find these words at all, but a word used something like a gesture, accompanying a complicated activity [43] (pp. 2, 7, 11).

An aesthetic experience without words does not mean a "tacit" experience, but a not (conceptually or emotionally) grounded experience. Even if AWO is sympathetic with all the attempts to shift from the illusory realm of nouns and substantial forms to the more fluid and loose range of verbs and adverbial forms, in fact, aesthetic experience often operates perfectly without any verbal language [21] (pp. 135-157). As the economist Piero Sraffa remarked to Wittgenstein, probably offering him a decisive starting point to change his earlier theory of language as a representation of facts based on a formal logical isomorphism between language and reality, gestures can be very expressive albeit not logically grounded. Haptic perception is not "implicit", nor "silent" or "tacit", as if it were defective, waiting for a conceptual integration. Instead, it can be perfectly expressive, noisy and even communicative [26] (pp. 227-242). There is a link, on the contrary, between the ontologically prefixed existence of the objects of OOO and the conceptual hypostatization expressed by words: Wittgenstein can help to dissolve this illusion placed in verbal language according to the AWO model here proposed.

Haptic perception is not about intention but attention. While intention is isolated and it focuses from the environment what it deems useful for the achievement of an objective, attention instead is diffused, process-oriented and relational because the perceiver is disposed to correspond with the environmental field as a whole. Intention is inter-active; attention is correspondent. The former is more into the verbal dialogue with a human being, the latter more into the engagement that Manning and Massumi propose to call 
entertainment, that is, a participation with the surroundings. For attention being oriented not to act directly but rather to correspond, haptic perception softens the focus about something specific and enhances the diffused entertainment with the processes. This weakening of the focus of intention also lowers the need for verbal expressiveness: haptic perception is usually less wordy than optic perception. Therefore, AWO is sympathetic with the aesthetics of infancy (the etymology of infancy is "inability to speak"). While conventional modern subject/object aesthetics has given little or no attention to infancy, AWO does.

There are, of course, many contributions to the relationship between expressiveness, knowledge and intersubjectivity in preverbal infancy, mainly from the fields of psychology, psychoanalysis and neurobiology, such as the contribution of Daniel Stern [44]. In the limited context of this paper, I cannot go into detail on this subject. I will limit myself to a brief mention in relation to what we have seen so far: why does the infant child not objectify nor theorize? Precisely because they experience the world in the haptic way, corresponding with undefined things and not perceiving them as fixed objects already given and made. Infant perception is aesthetic because it is a feeling/thinking with, dealing with everything-in-the-surroundings flow. There is no separation here between the thematic and the operational level, which will then be made by adult thinking. In the eighteenth century, Vico (one of the few aesthetic philosophers who gave importance to childhood) aptly observed in The New Science, comparing infantile thinking to poetry: "it is characteristic of children to take inanimate things in their hands and talk to them in play as if they were living persons" [45] (p. 186). In a different context, this is what Lambros Malafouris has called "thinging", to describe the attention to life "instantiated in acts of thinking and feeling with, through and about things" [46]. As we have seen above, "thinging" is another way to say that even things share their vibrant agency, and such sharing can produce those vibrant correspondences that are the aesthetic experiences. It is a sympathetic process. With the words of the architect and theorist Lars Spuybroek, "sympathy is what things feel when they shape each other" [47].

In order to describe the perception of the infant child, Ingold draws a difference between two modalities of movement: the maze and the labyrinth. Children often wander around streets without any intentions or fixed positions; they just move by curiosity and, sometimes, wonder. It is a moving from within, a whirling, haptically corresponding with distributed attention to the occurrences of life. Actually, corresponding is attending: to attend, to join with, to participate, ad tendere. In the other modality, the maze, intentions lead the way as the model in which design and prefixed ideas command, according to an agency where doing predetermines undergoing and actions prevail over passions. In the labyrinth, instead, life is not subservient to agency, because life is agencing without the prevalence of the I-agency [48]. The AWO model is sympathetic towards the aesthetics of infancy because they both share an animistic attitude. However, animism, in Andreas Weber's words, "is not about material objects being possessed by spirits" and by an individual soul. It is about "constructing a culture on principles that enable reciprocity, building on a cosmology, which integrates the experience of being part of a fecund collective" [49] (p. 23).

AWO is not an individual aesthetics. Haptic, process-oriented perception comes out from the enclosed cage of the self to free itself in the collective and shared field of the soul. Following another suggestion by Ingold [26] (pp. 52-60), while the self represents the individual ego, walled up and autonomous, the soul corresponds instead to the common fabric_cosmological, ontogenetic, phylogenetic - in which all the differences and the singularities grow and develop. The soul embraces the wholeness but, at the same time, lets continuously emerge the singularity of differentiating lives. Soul is the memory of the common background; the memory of the wholeness of the more-than-human world we inhabit. According to the AWO proposal, the aesthetic mind expresses the correspondence between the universality of the soul and the occurrence of a single perception. 


\section{Some Socio-Political and Meta-Aesthetic Consequences of AWO}

Coming at the end of this long proposal, in which there would naturally be many aspects to be explored and detailed further, I will briefly mention two kinds of consequences from the arguments presented above: they are of a socio-political and of a meta-aesthetic nature.

Let us begin with socio-political considerations. If one accepts the AWO approach, there is no room anymore for commodity fetishism. Process-oriented aesthetic perception supports Benjamin and Adorno's positions: a philosophy worthy of the name should free us from the tyranny of commodified objects. Hapticality operates on a different plane from that of the society of accumulation and capitalization: in a shared world of constitutively relational and cooperative experiences, even everyday perception is never individual. It goes without saying that even the individual fruition of works of art is questioned. In fact, since it contrasts ontological identity, the haptic approach also contrasts its sociopolitical correlate, property (at least understood in a "strong" sense, as capitalization and accumulation). Another comparison, by contrast to the $\mathrm{OOO}$ approach, may be useful: since it classifies, categorizes and creates multiple ontologies, object-oriented and optical perception leads to the generation of autonomous objects: a "phantasmagoria" (to recall again Benjamin) of objects, both human and non-human. Therefore, despite claiming its opposition to any human-centered politics [16] (p. 146), OOO brings up an aesthetics that is an ally to late capitalism in the age of advanced consumerism. The law of capital infiltrates everything: money (financial capital), culture (cultural capital), human beings (human capital) and philosophical minds.

On the other hand, however, AWO does not subscribe a "Power Politics" as opposed to "Truth Politics" (following the terminology proposed by Harman). As is explicit from the definition, Truth Politics claims to have a foundational and objective ground in rationality and in ontological principles, and, for this reason, it is not acceptable in an anti-foundational model such as AWO. However, Power Politics does not match either, remaining anchored to the modern ideology of force as the only law of movement-in onto-epistemology, ethics, aesthetics and politics. We have seen that force, being a movement from outside, presupposes a duality. In tune with contemporary physics, biology, and ecological philosophy, AWO questions the power of force, the power of Power, by suggesting replacing-or, at least, integrating - the force with the phase. The phase is not external; it is an oscillatory movement from within produced by life in each relationship of a field; it produces a polyphony of corresponding resonances. The phase is less noisy and mighty than force, less impactful; it operates according to minimal but no less effective displacements, on the contrary: the fluid perspective of an aesthetics without objects promotes the challenge of thinking of everyday experience as a field open to the greatest variations and evolutions. The everyday and the ordinary, perceived through the haptic, become extraordinary.

AWO can contribute to both the artistic practices and to the perception of the everyday; yet, "everyday perception" has to be understood not in the terms of the contemporary aestheticization of late capitalist society in which we live, but in the terms of a renewed artistic expression of everyday life. Actually, a relational and process-oriented approach is not only a scientific and philosophical issue, nor an onto-epistemic-ethical and aesthetic proposal; it is also a socio-political task. Therefore, AWO fits well in a social and economic model different from the one we are currently immersed in, matching an ideal of society and of culture that is not based on capitalization and accumulation and is not obsessed with property and consumption. Haptic perception is convivial in its nature, and sympathetic with a thought of finitude and sustainability: because of this, it calls for a conversion of perception.

What does a renewed artistic expression of everyday life correspond to? Note that haptic perception, as it is process-oriented, local and universal at the same time, is aesthetic and artistic because it is always also creative. Art has to be understood here, first, in all its socio-political pregnancy: the original meaning of art as téchne, craft and artisanship, fits perfectly and is adequate for the purpose. Once again, a comparison by contrast: object- 
oriented perception, being an expression of the fragmentation of the unity of life and the world into separated objects, is industrial because it aspires to generality, standardization, big scale, objectivity and predetermined objectives, and it runs in parallel with the birth of serial working time. It is not surprising that modern Western aesthetics is born objectoriented, being coeval with capitalist-industrial development. On the contrary, haptic perception is artisanal, being specific, local, small size, accurate, not governed by general rules, experiencing time from within as a task and creative. The art of thinking beautifully, to recover an expression of the founder, is a craft and a task. It cannot operate according to the industrial standards of repeatability and commodification. There are an industrial and an artisanal way of thinking: AWO is artisanal.

The feature described in the previous lines points out a subversion in the general conception of aesthetics that AWO carries with it: aesthetics has always been fluctuating between reflection about something (art or sensibility) and the operation with something. This duplicity was already clear since Baumgarten: aesthetics is "the science of sensitive knowledge" but also the "art of thinking beautifully", as we have just recalled. In other words, it is, at the same time, science and art; with different words: it is both thematic and operative [31], optic and haptic, spaced apart and engaged. However, aesthetics subsequently turned mainly-if not exclusively-to its optic/thematic side: a reflection on art, on aesthetic practices and on perception, more than an art of thinking and a peculiar modality of perception.

It might seem paradoxical to resort to artisanship in a project that promotes an aesthetics without objects, since it may seem granted that artisans have to do precisely with all different sorts of objects. However, the skilled artisan does not treat objects; they work with materials: materials are not "matter" as a substance ontologically fixed and predetermined. Working with materials means operating along processes in the flux of lines of correspondence. In his "Material Engagement Theory", Malafouris describes it through the notion of "thinging", that is, a relational agencing that is beyond cognitivism and representation:

I use the term Creative thinging to designate a long-term commitment to the discovery of new varieties of material forms, so far as it is possible in a given historical situation, through a saturated, situated engagement of thinking and feeling with things and form-generating materials. This working definition also implies that Creative thinging is not some kind of pregiven and static adaptation but is instead continuously generated and transformed in the constructive dialogue between maker and material. What I call Creative thinging can be understood as a species capacity for inventiveness that is inseparable from the capacity to affect and be affected through movement and sensation from the phenomenal qualities of the materials that surrounds us [46] (p. 144).

However, I want to add a further point to this description. These processes do not concern only the physical materials, their transformation and elaboration, but also the ongoing and generative field of immaterial matters: affects, imagination, memory, strategy, care, skills and the ability to improvise. In process-oriented aesthetic experiences, as in artisanship, the making of beauty and the beauty of making intertwine and correspond.

Let us come to the second consequences of $\mathrm{AWO}$, the ones concerning meta-aesthetics. What does it exactly mean to say that AWO is an artisanal and artistic approach per se, that is, an art of thinking beautifully? Stemming from what we have just argued about the features of aesthetic perception, it follows that AWO cannot be an aesthetic theory. However, what is a theory? I want to use two perspectives that, although apparently divergent, can both help to provide a consistent answer.

The first suggestion comes again from Wittgenstein. As it is well known, Wittgenstein masterfully expresses the meta-theoretical conception of his philosophical practice stating that philosophy should be made as a "poetic composition" ("Dichten"). However, I will recall here another illuminating passage from Remarks on Frazer's "The Golden Bough", as it fits perfectly the attitude I suggest taking up through AWO. Wittgenstein states: 
Was Augustine mistaken, then, when he called on God on every page of the Confessions? Well-one might say-if he was not mistaken, then the Buddhist holy-man, or some other, whose religion expresses quite different notions, surely was. But none of them was making a mistake except where he was putting forward a theory [50] (p. 1).

Wittgenstein connects his aversion to theory with the claim that there are no real mistakes in philosophy. Now, if we graft these two statements onto the aesthetic level, they allow us to understand why prefixed criteria cannot guarantee the occurrence of an aesthetic experience: it is its correspondence to make it true or false, intense or forgettable. According to Wittgenstein, both for the meaning of the words and for the aesthetic expressions, criteria and rules grow and develop along the lines of the experience: we make up the rules as we go along.

The same aversion for theory can be found also in the Lectures on Aesthetics:

Rhees asked Wittgenstein some question about his 'theory' of deterioration. Do you think I have a theory? Do you think I'm saying what deterioration is? What I do is describe different things called deterioration [43] (p. 10).

Wittgenstein understands philosophy as a therapy, that is, a way to break free from theory, seen as the (illusory) presumption of how things stand and the (illusory) systematic display of truth. Now, the Wittgensteinian move does not consist in the proposition of an alternative theoretical paradigm - and in a consequent new way of speaking and writing about it. Wittgenstein firmly states that everyday, ordinary language works perfectly as it is and that nothing must be changed in terms of its content. What we have radically to subvert, rather, is how we feel/think, that is, perceive. His philosophical therapy consists in a new modality of perception aiming to describe and clarify, and not to explain: observation without objectification. What makes the difference is the sensitivity we can infuse in the ordinary perception. Now, this is paramount for an AWO as an aesthetics from within: the immanence here at stake is not (or, at least, not just) about changing language and words or (just) re-shaping theoretical tools while living the same way. The challenge consists, rather, in a subversion of how we live without changing anything, that is, any "content" and any expressive forms. It is about how to see and how to listen, how to feel and, more importantly, how to live. It is a whole change of the system of values. Once again, it is about the pre-theoretical and non-intentional relationship that the infant has with the world.

However, what should we do then with our essays and our writings, with our philosophical tools that have been characterizing humans since ever, helping them to organize and re-shape their conceptual life continuously, in accordance with knowledge and science, if we cannot take them seriously? Of course, we have to take them seriously because we need them. Even Wittgenstein needed philosophizing about the "philosophical cramps" in order to dissolve them, and struggle never stops. Maybe then we can give the notion of "theory" another chance. According to David Bohm, "theories" are not systems for the knowledge of truth but ways of seeing the world, guides to perception. Elaborating in his own way the most radical consequences of quantum physics, Bohm fought for a non-fragmented conception of science and for an undivided wholeness in the conception of reality. He saw division and separations as illusions, originating from the attitude to perceive and think about things; although these illusions are useful tools for practical purposes, they should not be taken for realities with an autonomous existence:

When we deeply understand that our theories also work in this way, then we will not fall into the habit of seeing reality and acting toward it as if it were constituted of separately existent fragments corresponding to how it appears in our thought and in our imagination when we take our theories to be 'direct descriptions of reality as it is' [51] (p. 10).

Bohm assumes that wholeness is the only reality, and it is made of an "implicate order" in which everything is relational. In fact, he believes that experience and knowledge are the same. In this framework, theories are "ever changing forms of insight" [51] (p. 7) for the 
experience-knowledge paradigm. Unlike Wittgenstein, however, Bohm tried to elaborate an experimental language that was more consistent with the unitary/relational perspective of reality and called this language "Rheomode" (from the Greek verb "reo", to flow). The Rheomode aimed at showing what happens to language when we move from a structure based on nouns and on subject/verb/object to a structure based on processes, in which also verbs are used in a different way.

We can conclude by saying that AWO is certainly not an aesthetic theory in the Wittgensteinian sense; at the same time, AWO can be saved as a theory in the sense proposed by David Bohm, without endorsing the "Rheomode": a theory aware of its provisional function as an insight to provide "perspicuous representations" of the world. "Perspicuous representation" is, of course, another essential Wittgensteinian concept that fits very well into the AWO proposal: in fact, übersichtliche Darstellung means a type of perception-not only intellectual-which consists precisely in becoming able to see the connections of the same fabric of the grammatical contingency, in which differences between meanings, experiences and aesthetic occurrences are always recognized and created. AWO is thus two-faced: on the one hand, it cannot escape, as written language and conceptual reflection, being a theory of and about aesthetic issues; on the other hand, it is an aesthetic activity itself, a narration for better understanding and organizing life through concepts in a creative way. In this constative/performative interface, typical of every philosophy, AWO suggests an education to such perceptual ability, that is, to aesthetic perception as a perception that does not explain and analyze but sensitize to feel/think the universality and the wholeness into every singular correspondence of the interwoven lines of living. Beyond subjectivism and idealism, beyond objectivism and materialism, beyond subject/object phenomenalism, relational and process-oriented aesthetics, with its haptic approach, just aims at opening careful, attentive, passionate perception to the encounters along the fabric of the world.

Funding: This research received no external funding.

Conflicts of Interest: The author declares no conflict of interest.

\section{Notes}

1 The idea of Aesthetics Without Objects came to my mind through Tim Ingold, who suggests thinking to a World Without Objects (WWO) in opposition to the Object-Oriented Ontology (OOO) which I will talk about in the second section. See Ingold [1] (pp. 13-17). Another important source for the perspective expressed by the title is Berleant [2].

2 That said, I very much agree with some thesis promoted by Morton, especially with respect to his positions on ecological thought [14,15]. Moreover, his notion of "hyperobject" seems to have characteristics that correspond to what I will say here about the real as relational.

3 See also Perullo [37].

\section{References}

1. Ingold, T. The Life of Lines; Routledge: Abingdon, UK, 2015.

2. Berleant, A. Art without Object, in Creation and Interpretation; Stern, R., Rodman, P., Cobitz, J., Eds.; Haven: New York, NY, USA, 1985; pp. 63-72.

3. Sellars, W. Philosophy and the Scientific Image of Man. In Science, Perception and Reality; Routledge \& Kegan Paul: London, UK, 1963.

4. Rovelli, C. Helgoland; Allen Lane: London, UK, 2021.

5. Rovelli, C. The Old Fisherman's Mistake [Preprint]. Phil-Sci Archive. 2021. Available online: http://philsci-archive.pitt.edu/id/ eprint/18837 (accessed on 11 February 2022).

6. Gilbert, S.F.; Sapp, J.; Tauber, A.I. A Symbiotic View of Life: We Have Never Been Individuals. Q. Rev. Biol. 2012, 87, 325-341. [CrossRef] [PubMed]

7. Del Giudice, E. L'anima passionale della ragione scientifica; Biblion: Napoli, Italy, 2019.

8. Massumi, B. Semblance and Event: Activist Philosophy and the Occurrent Arts; MIT Press: Cambridge, MA, USA, 2011.

9. Barad, K. Meeting the Universe Halfway: Quantum Physics and the Entanglement of Matter and Meaning; Duke University Press: Durham, NC, USA, 2007.

10. Clark, A. Where brain, body, and world collide. Cogn. Syst. Res. 1999, 1, 5-17. [CrossRef]

11. Heldke, L. It's Chomping All the Way Down: Toward an Ontology of the Human Individual. Monist 2018, 101, 247-260. [CrossRef]

12. Weber, A. Enlivenment. Toward a Poetics for the Anthropocene; MIT: Cambridge, MA, USA, 2019. 
13. Meillassoux, Q. After Finitude: An Essay on the Necessity of Contingency; Continuum: London, UK, 2008.

14. Morton, T. Ecology without Nature. Rethinking Environmental Aesthetics; Harvard University Press: Cambridge, MA, USA, 2009.

15. Morton, T. The Ecological Thought; Harvard University Press: Cambridge, MA, USA, 2012.

16. Harman, G. Object-Oriented Ontology. A New Theory of Everything; Penguin Random House: London, UK, 2018.

17. Jornet, A.; Damsa, C. Unit of analysis from an ecological perspective: Beyond the individual/social dichotomy. Learn. Cult. Soc. Interact. 2021, 31, 1-10. [CrossRef]

18. Bourriaud, N. Inclusions: Aesthetics of the Capitalocene; Trans. by D. Beaulieu; Sternberg Press: Berlin, Germany, 2022.

19. Bennett, J. Vibrant Matter. A Political Ecology of Things; Duke University Press: Durham, NC, USA, 2010.

20. Noë, A. Strange Tools. Art and Human Nature; Hill and Wang: New York, NY, USA, 2015.

21. Desideri, F. La percezione riflessa. Estetica e filosofia della mente; Raffaello Cortina: Milano, Italy, 2011.

22. Desideri, F. Origine dell'estetico; Carocci: Roma, Italy, 2018.

23. Van Dijk, L. Psychology in an Indeterminate World. Perspect. Psychol. Sci. 2021, 16, 577-589. [CrossRef] [PubMed]

24. Jullien, F. There Is No Such Thing as Cultural Identity; Polity Press: Cambridge, UK, 2021.

25. Ingold, T. Knowing from the Inside. Correspondences; University of Aberdeen: Aberdeen, UK, 2017.

26. Ingold, T. Imagining for Real. Essays on Creation, Attention and Correspondence; Routledge: Abingdon, UK, 2022.

27. Perullo, N. Can Cuisine Be Art? A Philosophical (and Heterodox) Proposal, in The Taste of Art: Cooking, food, and counterculture in contemporary practices; Bottinelli, S., D'Ayala Valva, M., Eds.; The University of Arkansas Press: Fayetteville, NC, USA, 2017; pp. 23-44.

28. Berleant, A. The Aesthetic Field: A Phenomenology of Aesthetic Experience; Thomas: Springfield, IL, USA, 1970.

29. Dewey, J. Art as Experience (1934); Perigee: New York, NY, USA, 1980.

30. Miles, A.; Lessard, B.; Brasier, H.; Weidle, F. From Critical Distance to Critical Intimacy. Interactive Documentary and Relational Media. In Critical Distance in Documentary Media; Cammaer, G., Fitzpatrick, B., Lessard, B., Eds.; Palgrave Macmillan: London, UK, 2018; pp. 301-319.

31. Matteucci, G. Estetica e Natura Umana. La Mente Estesa tra Percezione, Emozione ed Espressione; Carocci: Roma, Italy, 2019.

32. Rovelli, C. Reality Is Not What It Seems; Penguin Books: London, UK, 2016.

33. Ingold, T. Correspondences; Polity Press: Cambridge, UK, 2020.

34. Manning, E. For a Pragmatics of the Useless; Duke University Press: Durham, NC, USA, 2020.

35. Deleuze, G.; Guattari, F. A Thousand Plateaus. Capitalism and Schizophrenia; University of Minnesota Press: Minneapolis, MN, USA, 1987.

36. Harney, S.; Moten, F. The Undercommons; Minor Compositions: London, UK, 2016.

37. Perullo, N. Ecological Aesthetics and Haptic Experience. In International Lexicon of Aesthetics; Mimesis Edizioni: Milan-Udine, Italy, 2021.

38. Perullo, N. The Experience-With: Steps Towards an Aesthetics from Within. Some Preliminary Notes. Reti Saperi Linguaggi, Ital. J. Cogn. Sci. 2020, 2, 241-257.

39. Merleau-Ponty, M. Eye and mind (1960), trans. by Dallery, C. In The Primacy of Perception, and Other Essays on Phenomenological Psychology, the Philosophy of Art, History and Politics; Edie, J.M., Ed.; Northwestern University Press: Evanston, IL, USA, 1964; pp. 159-190.

40. Manning, E.; Massumi, B. Thought in the Act, Passages in the Ecology of Experience; University of Minnesota Press: Minneapolis, MN, USA, 2014.

41. Goodman, A. Wilding Consciousness: Towards a speculatively Tentacular Thinking-With. AM J. Art Media Stud. 2020, $23,103-119$.

42. Berleant, A. Objects into Persons: The Way to Social Aesthetics. Espes: Aesthet. Between Art Soc.: Perspect. Arnold Berleant's Postkantian Aesthet. Engagem. 2017, 6, 9-18.

43. Wittgenstein, L. Lectures on Aesthetics. In Lectures and Conversation on Aesthetics, Psychology and Religious Belief; Barrett, C., Ed.; University of California Press: Los Angeles, CA, USA, 1965.

44. Ammaniti, M. Implicit Knowledge from Infancy to the Psychotherapeutic Relationship: The Contribution of Daniel Stern. Psychoanal. Inq. 2018, 38, 138-147. [CrossRef]

45. Vico, G. The New Science; Translated from the third edition (1744) by Bergin, T.G. and Fisch, M.H.; Cornell University Press: Ithaca, NY, USA, 1948.

46. Malafouris, L. Creative thinging. The feeling of and for clay. Pragmat. Cogn. 2014, 22, 140-158. [CrossRef]

47. Spuybroek, L. The Sympathy of Things. Ruskin and the Ecology of Design; Bloomsbury: London, UK, 2011.

48. Ingold, T. The maze and the labyrinth: Walking, imagining and the education of attention. In Psychology and the conduct of everyday life; Schraube, E., Højholt, C., Eds.; Routledge: London, UK, 2016; pp. 99-110.

49. Weber, A. Sharing Life. The Ecopolitics of Reciprocity; Heinrich Böll Stiftung: Berlin, Germany, 2020.

50. Wittgenstein, L. Remarks on Frazer's 'The Golden Bough'; Rees, R., Ed.; Brynmill Press: Retford, UK, 1979.

51. Bohm, D. Wholeness and the Implicate Order; Routledge \& Kegan Paul: Abingdon, UK, 1980. 